\title{
Environmental Awareness, Environmental Knowledge, and Environmental Promotion by the Government towards Environment Friendly Concept on Semarang Small and Medium Enterprises
}

\author{
Robetmi Jumpakita Pinem ${ }^{1}$, Muhammad Faizal Alfian ${ }^{2}$ \\ \{robetmi@lecturer.undip.ac.id ${ }^{1}$ \} \\ Universitas Diponegoro, Indonesia ${ }^{1,2}$
}

\begin{abstract}
Environmental problem is one of the issues that continues to be hot every year because it has a direct influence on human life. The environment is currently the concern of many people, both individually, community groups, organizations and other parties. The very large number of MSEs, especially the food and beverage business, has great potential to produce waste. Currently, the problem of plastic waste is one of the government's concerns, giving an appeal to reduce the use of plastic waste, especially for shopping at supermarkets. Several food and drink places have started to implement environmental care by doing a variety of ways. Some examples include not providing a straw, changing plates or disposable food containers into containers that can be used multiple times. This research uses a combination of quantitative and qualitative research. In this study, the population is MSMEs in Central Java, Indonesia. This study only takes a few people who are representative. The sample used must be able to represent and reflect the existing population. The number of samples in this study were 30 respondents, namely small and medium enterprises in the city of Semarang who have implemented an environmentally friendly concept in the businesses they run. The analysis technique used in this study is a quantitative analysis technique, the aim is to estimate the quantitative effect of changes in one or several other events using Lisrel software tool. Used to test the validity and reliability test, test coefficient, regression test and coefficient of determination. The amount of Environmental awareness, Environmental knowledge and Environmental Promotion towards the exogenous latent variable Environmental Concept is shown by the $R$ square value (R2), the $R$ square value 0.80 shows the contribution/effect of Environmental awareness, Environmental knowledge and Environmental Promotion to the Environmental Concept of $80.0 \%$, the remaining $20.0 \%$ is influenced by other factors.
\end{abstract}

Keywords: Environmental, Awareness, Knowledge, Promotion, SMEs

\section{Introduction}

Environmental problem is one of the issues that continues to be hot every year because it has a direct influence on human life. The environment is currently the concern of many people, both individually, community groups, organizations and other parties. In online reporting, if we do a search on the google search engine "Environmental Problems in 
Indonesia 2019", the results quickly come out $123,000,000$ results ( 0.36 seconds). This is proof that in Indonesia there are still many environmental issues.

Currently, many efforts are being made to reduce environmental damage in Indonesia which are carried out individually or in groups. Many governments or private parties are carrying out activities to improve the environment in Indonesia. Even though a lot of efforts have been made, the environmental damage caused by humans continues to exist. Many actors, either individually or in groups, are not aware of environmental damage.

The number of restaurants and beverages including those selling street food in Indonesia has a very large number. It can be seen in table 1 data based on data from the Indonesian Ministry of Cooperatives and MSMEs. The number of MSEs recorded in the Indonesian economic census in 2016 was 26,073,689 and as many as 4,431,154 Micro and Small Businesses in the food and beverage business sector (Economic Census, 2016), while MSEs in the food and beverage sector also certainly did not enter the data collection.

The very large number of MSEs, especially the food and beverage business, has great potential to produce waste. Currently, the problem of plastic waste is one of the government's concerns, giving an appeal to reduce the use of plastic waste, especially for shopping at supermarkets. The big question at this time is how the production of plastic waste by micro and small businesses is very large. The ratio of waste produced by large companies is indeed very different in quantity. The small amount of plastic waste produced by 1 micro and small business multiplied by the number of micro and small businesses will produce a very large amount of waste.

Micro and small businesses in the food and beverage sector use a lot of straws, plastic bags, Styrofoam and other containers used for food containers. Based on observations in Tembalang, Central Java, Indonesia, which is one of the places where there are many micro and small-scale food and beverage sellers. Many sellers who still use straws when serving food and drinks still use straws and disposable food containers.

Tembalang is an area that is inhabited by many students because of the location of several universities so that there are many food and beverage sellers in the area. The increase in the number of students will certainly increase the number of food and beverage sellers and will certainly increase the amount of waste generated every day. Tens of thousands of students will purchase food and drinks every day and add up how much waste is produced each day, even though the processing is still not optimal.

Several food and drink places have started to implement environmental care by doing a variety of ways. Some examples include not providing a straw, changing plates or disposable food containers into containers that can be used multiple times. A small proportion of the number of food and beverage sellers have indeed started good steps to reduce environmental damage due to waste. If you pay attention, there are still many food and beverage sellers who do not reduce the use of plastic. Based on the description of the background, the formulation in this study is as follows: Awareness, how is the Influence of Environmental Awareness, Knowledge, and Promotion on the Application of Environmentally Friendly Concepts in Small and Medium Enterprises in Semarang City. 


\section{Literature}

\subsection{Environmental Awareness}

Environmental awareness according to Webster, Follows and Jobber [1] is a consumer who remembers the general consequences of personal or business consumption. Environmental awareness is a form of concern from the community to have a better view of the surrounding environment. There are so many good things that arise when people have environmental awareness, one of which is by having a green product buying behavior.

Consciousness is formed if it has understanding. Consumers who have environmental awareness are those who understand or have insight into the environment. In his research, Wibowo [2] has collected a theory that defines environmentally friendly consumers as follows: 1) Types of consumers whose purchasing behavior is influenced by their orientation towards the environment [3]. 2) Consumers who pay attention to the impact of the production process and product consumption on the environment [4]. 3) Consumers who are environmentally friendly as consumers who have pro-environmental values and attitudes [5].

\subsection{Environmental Knowledge}

Environmental knowledge refers to individual knowledge about the effect of a product on the environment, and in particular for the process of evaluating the features and benefits of a product in an environmental context [6]. People with broader environmental knowledge will be more concerned about environmental damage and will be more willing to buy organic food. Environmental knowledge is an important factor in understanding consumers who intend to buy organic food, as it represents a situation in which consumers consider the benefits of purchasing for themselves and the environment [7].

\subsection{Environmental Promotion}

The role of government is very big in increasing public awareness to participate in preserving the environment. Micro, small and medium business activities, especially in the culinary sector, produce waste. Two ministries, namely the Ministry of Cooperatives and Micro, Small and Medium Enterprises (UKM) and the Ministry of Environment create a synergy in the form of a memorandum of understanding (MoU) Number: PKS.1/MENLHK/PSLB3/PSLB/0/3/2016 and Number: 05/KB/M/KUKM/III/2016 concerning Environmental-based Cooperative and Micro, Small, and Medium Enterprises Empowerment Programs.

Environmental-based Cooperative and Micro, Small and Medium Enterprises (UKM) Empowerment Program. The Waste Bank management program by these two ministries includes socialization of capacity building for waste banks to become cooperatives and SMEs. The government synergizes to socialize waste reduction including reducing the use of singleuse tools so that waste reduction can be carried out by micro, small and medium enterprises. 


\section{Method}

This research uses a combination of quantitative and qualitative research. Quantitative research uses explanatory research type, while qualitative research conducts dept interviews with research respondents, both government parties, the private sector and SMEs. Explanatory research aims to explain the relationship between two or more symptoms or variables. Population is a generalization area consisting of objects or subjects that have certain quantities and characteristics that are determined by the researcher to study and then draw conclusions [8].

In this study, the population is MSMEs in Central Java, Indonesia. This study only takes a few people who are representative. The sample is part of the total characteristics of the population [8]. The sample used must be able to represent and reflect the existing population. The number of samples in this study were 30 respondents, namely small and medium enterprises in the city of Semarang who have implemented an environmentally friendly concept in the businesses they run. The analysis technique used in this study is a quantitative analysis technique, the aim is to estimate the quantitative effect of changes in one or several other events using the Lisrel software tool. Used to test the validity and reliability test, test coefficient, regression test and coefficient of determination.

\section{Results and Discussion}

The number of samples in this study were 30 respondents, namely small and medium enterprises in the city of Semarang who have implemented an environmentally friendly concept in their business. Respondent male and female.

\subsection{Analysis of the Validity and Reliability of Confirmatory Factors}

Confirmatory factor analysis aims to test the un-dimensionality of the forming indicators of each latent variable. The following are the results of the confirmatory factor analysis of each model. The author uses Confirmatory Factor Analysis (CFA) with the help of Lisrel software.

Table 1. Confirmatory Factor Analysis (CFA)

\begin{tabular}{|c|c|c|c|c|c|c|}
\hline Variable & Indicators & $\lambda$ & $\lambda^{2}$ & $\mathbf{e}$ & $\mathbf{C R}$ & VE \\
\hline \multirow{5}{*}{ Environmental awareness } & $\mathrm{X} 1$ & 0.56 & 0.3136 & 0.08 & \multirow{5}{*}{0.92} & \multirow{5}{*}{0.7} \\
\hline & $\mathrm{X} 2$ & 0.78 & 0.6084 & 0.05 & & \\
\hline & $\mathrm{X} 3$ & 0.74 & 0.5476 & 0.12 & & \\
\hline & $\mathrm{X} 4$ & 0.53 & 0.2809 & 0.53 & & \\
\hline & $\mathrm{X} 5$ & 0.52 & 0.2704 & 0.12 & & \\
\hline \multirow{4}{*}{$\begin{array}{l}\text { Environmental } \\
\text { knowledge }\end{array}$} & X6 & 0.52 & 0.2704 & 0.69 & \multirow{4}{*}{0.79} & \multirow{4}{*}{0.5} \\
\hline & $\mathrm{X} 7$ & 0.59 & 0.3481 & 0.4 & & \\
\hline & $\mathrm{X} 8$ & 0.56 & 0.3136 & 0.36 & & \\
\hline & $\mathrm{X} 9$ & 0.71 & 0.5041 & 0.09 & & \\
\hline \multirow{3}{*}{ Environmental Promotion } & $\mathrm{X} 10$ & 0.89 & 0.7921 & 0.01 & \multirow{3}{*}{0.95} & \multirow{3}{*}{0.8} \\
\hline & $\mathrm{X} 11$ & 0.81 & 0.6561 & 0.03 & & \\
\hline & $\mathrm{X} 12$ & 0.57 & 0.3249 & 0.43 & & \\
\hline
\end{tabular}




\begin{tabular}{|c|c|c|c|c|c|c|} 
& $\mathrm{X} 13$ & 0.68 & 0.4624 & 0.17 & & \\
\cline { 2 - 6 } & $\mathrm{X} 14$ & 0.65 & 0.4225 & 0.11 & & \\
\hline \multirow{5}{*}{ Environmental Concept } & $\mathrm{Y} 1$ & 0.55 & 0.3025 & 0.06 & & \\
& $\mathrm{Y} 2$ & 0.78 & 0.6084 & 0.14 & & \\
& $\mathrm{Y} 3$ & 0.73 & 0.5329 & 0.02 & \multirow{3}{*}{0.98} & \multirow{3}{*}{0.9} \\
& $\mathrm{Y} 4$ & 0.55 & 0.3025 & 0.08 & & \\
\cline { 2 - 6 } & $\mathrm{Y} 5$ & 0.69 & 0.4761 & 0.07 & & \\
\hline & $\mathrm{Y} 6$ & 0.76 & 0.5776 & 0.03 & & \\
\hline
\end{tabular}

The table above shows that the loading factor for each construct indicator is greater than 0.5. This means that each indicator is declared valid in forming variable constructs. Then CR (construct reliability) must be above 0.7 and VE (variance extracted) must be above 0.5 , so it can be concluded that the variable construct has good construct validity and reliability.

\subsection{Full Model Testing Results}

This section describes the results of the evaluation of the fit model and the estimated parameter values of the structural equation model. The empirical model generated from the theoretical model in this study requires full model testing. After the confirmatory factor analysis for each of the exogenous and endogenous variables is carried out, it is necessary to estimate the full structural model. The full structural model estimation analysis illustrates the relationship between latent variables and can be done if the measurement model has been analyzed through confirmatory factor analysis. This is because each indicator can be used to define a latent construct. The full structural model estimation results are presented in the following figure.

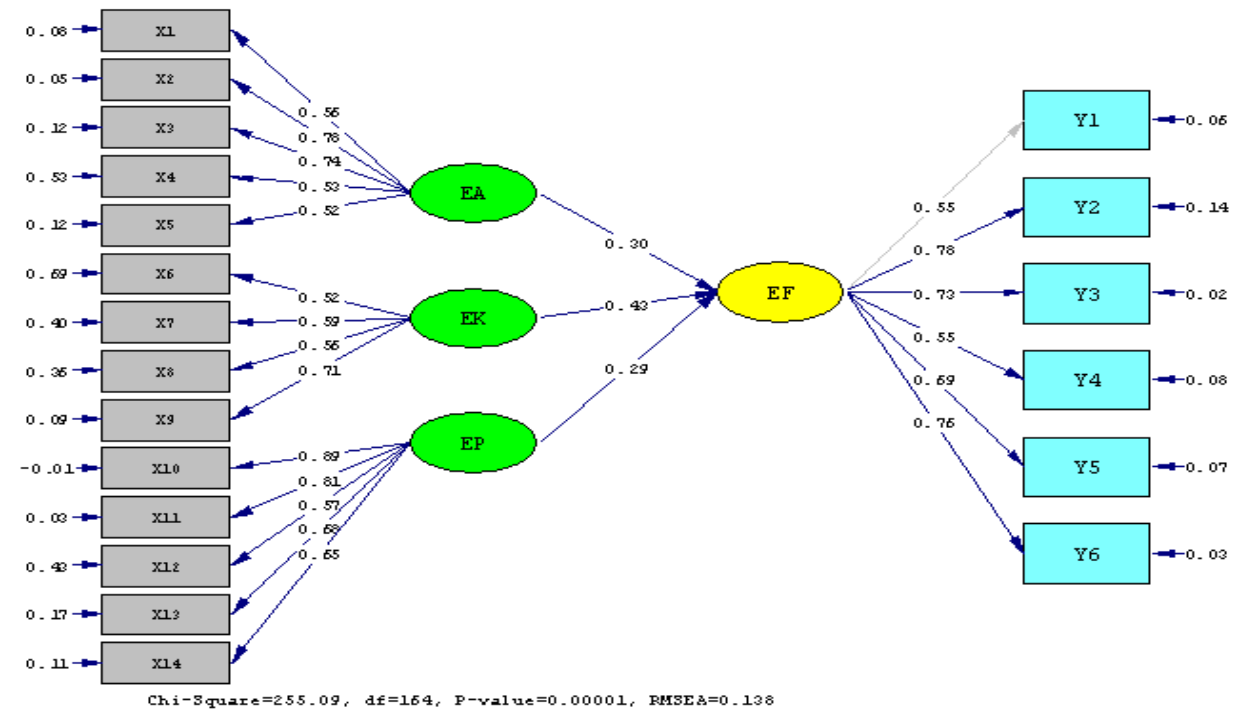

Fig. 1. The results of the full structural model (Standardized). 
The results on the structural equation are presented in the image above. SEM model testing is carried out by two kinds of tests, namely the suitability of the model and the significance of causality through the regression coefficient. SEM model testing is used to see the feasibility of the model or the suitability of the model. The model suitability indices used were not different from the indices in the confirmatory factor analysis. Based on the results of the model above, the chi-square value $=255.09 \mathrm{df}=164$, $\mathrm{p}$-value $=0.00001$ and $\mathrm{RMSEA}=$ 0.138 . To find out whether the structural model developed has been supported by data, a goodness of fit test is performed. The following are the results of the goodness of fit test on the structural model.

Table 2. Goodness of Fit Research Model

\begin{tabular}{|c|c|c|c|}
\hline Good of Fit Index & Result & Critical value & Conclusion \\
\hline Cisquare/DF & 2 & $2<\mathrm{X}^{2} / \mathrm{df}<5$ & Good Fit \\
\hline CFI & 0.9 & $\geq 0,9$ & Good Fit \\
\hline GFI & 0.53 & $\geq 0,9$ & Bad Fit \\
\hline AGFI & 0.40 & $\geq 0,9$ & Bad Fit \\
\hline RMSEA & 0.14 & $\leq 0.08$ & Bad Fit \\
\hline RMR & 0.065 & $\leq 0.05$ & Bad Fit \\
\hline
\end{tabular}

In the table above, the test results for the fit model see the values of Cisquare/DF, CFI, GFI, AGFI, RMSEA and RMR. This study has met the criteria because the value tested for 2 out of 6 values is good so that the model is declared feasible for further processing.

\subsection{Hypothesis testing}

$$
\begin{aligned}
& \text { Equation } \\
& \mathrm{EF}=0.30 * \mathrm{EA}+0.43 * \mathrm{EK}+0.29 * \mathrm{EP}, \\
& \text { Errorvar }=0.20, \mathrm{R}^{2}=0.80 \\
& \begin{array}{llll}
(0.14) & (0.18) & (0.18) & (0.072)
\end{array} \\
& \begin{array}{llll}
2.21 & 2.34 & 1.61 & 2.78
\end{array}
\end{aligned}
$$

The coefficient of the exogenous latent variable Environmental awareness of the exogenous latent variable Environmental Concept is 0.30, indicating a positive direction of relationship between Environmental awareness and Environmental Concept, meaning that when Environmental awareness is good, the Environmental Concept will be good. The t count value of 2.21 is greater than the specified critical limit, which is \pm 1.96 , so H0 is rejected, which means that there is an influence of Environmental awareness on the exogenous latent variable Environmental Concept. The coefficient of the exogenous latent variable of Environmental knowledge on the exogenous latent variable of Environmental Concept is 0.43, indicating a positive direction of relationship between Environmental knowledge and Environmental Concept, meaning that when Environmental knowledge is good, the Environmental Concept will be good. The t value of 2.34 is greater than the specified critical limit, which is \pm 1.96 , so that $\mathrm{H} 0$ is rejected, which means that there is an influence of Environmental knowledge on the exogenous latent variable Environmental Concept. The coefficient of the environmental exogenous latent variable of Environmental Promotion for the exogenous latent variable of Environmental Concept is 0.29 , indicating a positive direction of relationship between Environmental Promotion and Environmental Concept, meaning that when the Environmental Promotion is good, the Environmental Concept will be good. The $\mathrm{t}$ 
count value of 1.61 is smaller than the specified critical limit, which is \pm 1.96 , so that $\mathrm{H} 0$ is accepted, which means that there is no effect of Environmental Promotion on the exogenous latent variable of Environmental Concept. The amount of Environmental awareness, Environmental knowledge and Environmental Promotion towards the exogenous latent variable Environmental Concept is shown by the R square value (R2), the R square value 0.80 shows the contribution/effect of Environmental awareness, Environmental knowledge and Environmental Promotion to the Environmental Concept of $80.0 \%$, the remaining $20.0 \%$ is influenced by other factors.

Based on the data collected, all micro, small and medium business actors in the food sector have a concern in the environmental sector, that all business actors have a concern for current environmental damage. All business actors who are research respondents are trying to reduce waste reduction as a form of protecting the environment. Most of the business actors answered that they were very confident of contributing to reducing environmental harm. Most business actors firmly believe in reducing environmental damage than businesses run by others. This proves that business actors continue to strive to protect the environment, one of which is as business actors to reduce the use of materials that can cause increased waste.

Most business actors strongly agree that humans protect the environment. Humans are responsible for environmental sustainability. This answer is in line with the previous answer that business actors are indeed trying to protect the environment by reducing waste from their business activities. Most business actors have the desire to always have a contribution to protecting the environment. This shows that the commitment of business actors is very important to protect the environment by reducing the use of waste from the business they are running. Millions of micro and small businesses in Indonesia will be greatly helped to reduce waste by maintaining a shared commitment.

Most business actors try to use tools or materials that can be used repeatedly. This shows that commitment to protecting the environment can be seen from the actions taken by business people. Most of the food and beverage business actors no longer use drinking straws to reduce waste. This is clear evidence that micro and small business actors have taken action to reduce waste due to the use of disposable materials or tools. There are still businesses that use straws even though they have tried to reduce them or not offer straws if they are not requested by consumers. The commitment of business actors is indeed very important to educate the public to take real action to reduce waste to protect the environment.

Some micro and small businesses no longer use plastics for consumers, but there are still businesses that use plastic bags because they have not found a plastic substitute for food containers when consumers buy online. Based on field observations, it is indeed difficult for business actors not to use plastic bags when consumers buy food or drinks without plastic bags. Currently it is important for all stakeholders to be able to think of ways not to use plastic bags totally because plastic bags are one of the most waste products generated from micro, small and medium enterprises.

Most business actors strongly agree that business people strongly agree that it is very important for business actors to use non-disposable products in the production process or in the process of selling to consumers. Most business operators strongly agree that the use of disposable plates and tools can damage the environment. This understanding is very important because business actors are the spearhead of a business that is committed to protecting the environment by reducing the contribution of waste from the business it runs. Most business actors have very often heard the recommendation from the government on the importance of protecting the environment by reducing waste. Business actors are increasingly aware of the government's recommendation to protect the environment by reducing the use of plastic as a 
source of waste. It is important for the government to continue to disseminate information to the community to jointly protect the environment.

\section{Conclusion}

The number of restaurants and beverages including those selling street food in Indonesia has a very large number. The very large number of MSEs, especially the food and beverage business, has great potential to produce waste. Currently, the problem of plastic waste is one of the government's concerns, giving an appeal to reduce the use of plastic waste, especially for shopping at supermarkets. Micro and small businesses in the food and beverage sector use a lot of straws, plastic bags and other containers used for food containers. Tens of thousands of students will purchase food and drinks every day. Several food and drink places have started to implement environmental care by doing a variety of ways.

Based on the data collected, all micro, small and medium business actors in the food sector have a concern in the environmental sector, that all business actors have a concern for current environmental damage. Most business actors strongly agree that humans protect the environment. Humans are responsible for environmental sustainability. Most business actors try to use tools or materials that can be used repeatedly. This shows that commitment to protecting the environment can be seen from the actions taken by business people. Most of the food and beverage business actors no longer use drinking straws to reduce waste. This is clear evidence that micro and small business actors have taken action to reduce waste due to the use of disposable materials or tools.

The amount of Environmental awareness, Environmental knowledge and Environmental Promotion towards the exogenous latent variable Environmental Concept is shown by the $\mathrm{R}$ square value (R2), the R square value 0.80 shows the contribution/effect of Environmental awareness, Environmental knowledge and Environmental Promotion to the Environmental Concept of $80.0 \%$, the remaining $20.0 \%$ is influenced by other factors.

\section{References}

[1] B. F. Scott and D. Jobber, "Environmentally responsible purchase behaviour: a test of a consumer model," Eur. J. Mark., vol. 34, no. 5/6, pp. 723-746, 2000.

[2] S. F. Wibowo, "Karakteristik Konsumen Berwawasan Lingkungan dan Hubungannya dengan Keputusan Membeli Produk Ramah Lingkungan,” Econosains J. Online Ekon. dan Pendidik., vol. 9, no. 2, pp. 192-202, 2011.

[3] L. J. Shrum, J. A. McCarty, and T. M. Lowrey, "Buyer characteristics of the green consumer and their implications for advertising strategy," J. Advert., vol. 24, no. 2, pp. 71-82, 1995.

[4] G. M. Zinkhan and L. Carlson, "Green advertising and the reluctant consumer," J. Advert., vol. 24, no. 2, pp. 1-6, 1995.

[5] J. Moisander and S. Pesonen, "Narratives of sustainable ways of living: constructing the self and the other as a green consumer," Manag. Decis., 2002.

[6] W. Akbar, S. Hassan, S. Khurshid, M. Niaz, and M. Rizwan, "Antecedents affecting customer's purchase intentions towards green products," J. Sociol. Res., vol. 5, no. 1, pp. 273-289, 2014.

[7] Z. S. Saleki, M. S. Seyedeh, and M. R. Rahimi, "Organic food purchasing behaviour in Iran," Int. J. Bus. Soc. Sci., vol. 3, no. 13, 2012.

[8] Sugiyono, Metode Penelitian Kuantitatif, Kualitatif dan R\&D. Penerbit Alfabeta Bandung, 2010. 